\title{
INDIA: \\ UNA APASIONADA FAMILIA HUMANA \\ (APUNTES)
}

\section{Santiago Gamboa}

Luego de vivir más de un año en la India, el escritor y ensayista colombiano Santiago Gamboa relata en estas páginas vivencias y reflexiones de su estadía en la India. Comenzando por las que eran sus expectativas antes de llegar a Nueva Delhi, siguiendo con sus primeras impresiones y luego con sus reflexiones una vez instalado en la ciudad, Gamboa nos entrega una mirada penetrante de las culturas y creencias que acompañan a las contradicciones, horror y belleza, miserias y riquezas de la India.

Palabras clave: India; Nueva Delhi; escritos sobre la India; V. S. Naipaul.

Santiago Gamboa. Escritor colombiano. Estudió literatura en la Universidad Javeriana de Bogotá, y literatura cubana en la Universidad de la Sorbona, París. Licenciado en filología hispánica en la Universidad Complutense, Madrid. Fue corresponsal del periódico El Tiempo en París, columnista y colaborador de varias revistas. Autor, además de cuentos y relatos de viajes, de las novelas Páginas de Vuelta (1995), Perder es Cuestión de Método (1997), Los Impostores (2001), El Síndrome de Ulises (2005), Hotel Pekín (2008) y Necrópolis (2009). Fue miembro de la delegación de Colombia en la Unesco y de la embajada colombiana en la India. Actualmente vive en Italia.

Estudios Públicos, 119 (invierno 2010). 


\section{Q}

sto ocurrió en una extraña época de mi vida. Era diplomático y hacía poco vivía en Nueva Delhi, una ciudad que para un latinoamericano no era nada convencional y, por eso, creía yo, exigía un cierto talante aventurero. Era lo que pensaba en esos días. Había pasado demasiado tiempo en Europa, ¡veinticuatro años!, diciéndome que si en verdad fuera un hombre osado - como quería e incluso creía serdebía haberme ido a vivir hacía mucho a lugares más fieros y lejanos como Pekín, Jakarta o Nairobi. Tras un largo período de formación, búsqueda de estabilidad y logro de un cierto nivel de flotación en Europa, ya estaba listo para salir, perderme y perder lo adquirido o cambiarlo por experiencias que ansiaba vivir. Por eso cuando se me propuso el cargo de consejero, encargado de funciones consulares en la embajada de Colombia ante la India, mi mujer y yo no lo dudamos ni un segundo y empezamos a prepararnos para abandonar el Continente Triste con nuestro pequeño hijo Alejandro, nacido hacía un año y medio en París.

Todo fue alegría, esperanzas y el deseo de una nueva vida. Nos las prometíamos muy felices, pero la realidad siempre lo pone a uno en su sitio. En vista del paupérrimo sueldo del cargo - cifra que el decoro me impide precisar, como diría Julio Ramón Ribeyro - no pudimos instalarnos en las tradicionales zonas de extranjeros como Vasant Vihar, Sundar Nagar o Nizzamudin East, sino elegir algo más económico en Jangpura Extention, un barrio de clase media que al principio me pareció polvoriento y algo tremebundo, y al final, como suele suceder, acabé queriendo. Uno se acostumbra a todo, incluso al hecho de que a doscientos metros de su casa haya una esquina repleta de ruidosos rickshaws, perros dormidos, taxis destartalados, un infecto orinal del que emergen nubes de zancudos y friterías de calle que parecían fábricas de tifo o disentería.

Las oficinas de la embajada estaban en Vasant Vihar, un barrio rico aunque repleto de polvo y con el inconveniente de estar justo debajo de la línea de descenso de los aviones que van a posarse al aeropuerto Indira Gandhi, con lo cual más o menos cada tres minutos era necesario gritar para oírse de un lado a otro de una habitación. Y esto no era todo: el frontis del edificio daba a la avenida Olof Palme, en la cual, durante un tiempo demencialmente largo, bulldozers y grúas construían un puente - llamado "fly over" en inglés de la India - gigantesco pro- 
duciendo increíbles montañas de polvo, ruido de taladros y terroríficos olores a cañería, sin hablar de los atascos. El paroxismo llegó el día en que, tal vez por las excavaciones para echar los cimientos del "fly over", una serpiente de dos metros y quince centímetros de diámetro atravesó la Olof Palme Marg y llegó a las puertas de nuestra embajada, donde murió herida por las ruedas de un camión cuyo chofer, por cierto, se detuvo y lloró por el accidente, agarrándose la cabeza con las dos manos, pues en India toda expresión de la vida es sagrada.

En el segundo piso de la Olof Palme Marg estaba mi oficina, con vista a los jardines de una empolvada mansión que era la embajada del Emirato de Bahrein, y cada vez que miraba por la ventana o salía a mi portentoso balcón veía a dos guardias y a un perro dormir en las garitas de seguridad. La función consular consistía en firmar visas para ciudadanos indios que iban a Colombia a hacer negocios, visitas técnicas, de estudios o, raramente, de turismo. Otra de las obligaciones era tramitar unos documentos llamados "exhortos" para la oficina nacional de impuestos, en la práctica legalización de facturas hechas por compañías colombianas a empresas de India, Bangladesh y Pakistán, e incluso de Irán, Myanmar, Sri Lanka y Nepal, los países en los que éramos concurrentes.

Mi colaboradora, Olympia León de Singh, era una mujer entrada en la cincuentena que llevaba en la oficina más de diez años y conocía los entresijos de la "función consular", además de ser la única que hablaba hindi, pues estaba casada con un sikh del que se había enamorado veinticinco años atrás, en la Universidad Patricio Lumumba de Moscú, donde estudió Relaciones Internacionales. Sus historias, que soltaba con cuentagotas y sólo cuando su terrible genio de santandereana amainaba, eran geniales. Contaba que a principios de los ochenta las embajadas traían el papel higiénico por valija diplomática; que las calles eran de tierra y sólo había automóviles Ambassador; que la proporción de leprosos y poliomielíticos era de cinco a uno comparado con lo que se ve hoy. Y yo le creía, pues por esos años un conocido hizo una escala en Delhi, viajando hacia Japón, en la que los pasajeros que continuaban debían permanecer en el avión, y contaba aterrado cómo durante la espera una multitud de pordioseros, tullidos y enfermos subieron al aparato a pedir limosna, jen la pista del aeropuerto!

Olympia, con su formación comunista, contaba lo que era el Moscú de los años setenta y los ojos le brillaban: la ciudad de la abun- 
dancia, de la exquisitez, de la cultura y el arte. En esos mismos años Delhi era todo lo contrario: un poblachón inmenso transitado por carretas de bueyes y calles sin asfaltar, donde la gente moría de escorbuto y diarrea y donde enfermedades que en la Unión Soviética eran raras, como la lepra, aún estaban al orden del día y florecían a diario. Esto era esencialmente cierto y lo sigue siendo, pues mi trayecto cotidiano desde Jangpura hasta Vasant Vihar incluye un semáforo con los siguientes personajes: un leproso envuelto en una túnica ensangrentada y tres muñones en el lugar de los dedos; dos eunucos que debieron haber sido expulsados de su zona; una mujer que enseña a un bebé con la mano quemada — que según me hizo ver Peter, mi conductor, era falsa, fabricada con mantequilla y gelatina, cosa que me alegró- y vendedores de revistas, parasoles, corbatas y pañuelos. Una de las primeras imágenes al llegar a Delhi fue la de un hombre muy delgado, en Chandni Chowk, que exhibía con absoluta insistencia un testículo elefantiásico y un prolaxo rectal, dos melones colgando de un cuerpo flaco y atormentado, como las levas de un humano reloj de pared. Habiendo visto el bazar de humanidades que se aglomera en las escalinatas que ascienden a la mezquita de Jama Masjid, lo que incluye a un enano que sufre de polio y a varios leprosos en estado grave, era evidente que en Delhi, la inquietante y hermosa Delhi, las enfermedades y las deformidades daban a los sufrientes un modo estable de ganarse la vida.

Pero volvamos a Olympia, pues era ella quien me traía a diario los problemas que era necesario resolver, tanto con los visados como con la comunidad de connacionales, sustancialmente formada por pilotos que trabajaban en la compañía india Kingfisher, jóvenes que venían a hacer pasantías en compañías indias y, sobre todo, los adeptos del "turismo espiritual", que en su mayoría eran señoras ricas que encontraban alivio en las enseñanzas de Sai Baba, Osho y otros filósofos contemporáneos que desde la India daban consejos de vida y fórmulas sabias sobre la identidad o la paz o el amor, conceptos que en el mundo occidental eran recibidos como agua bendita.

Una vez Olympia llegó a mi oficina muy alterada y me dijo, jefe, venga y oiga esto. Fui a la sala de recepción del público, donde me esperaba un indio de edad mediana bastante nervioso. Traía el pasaporte de una colombiana de veintisiete años que, según dijo, "tenía problemas", y al preguntarle de qué tipo contó que era una devota del gurú Ravi Ravindra y que, tras un "seminario espiritual", su mente estaba 
algo rara, con problemas. ¿De qué índole?, quise saber, y el hombre, bajando los ojos, confesó: quiere salir a la calle desnuda, no duerme, está obsesionada con Ravi, dice que va a ser su mujer, que se quiere ir con él a Indonesia, en fin.

Fui de inmediato a ocuparme del caso. La tenían en un apartamento cerca de Green Park. Al verme me dijo, hola, ¿quieres tomar algo?, ¿quieres comer?, siéntate, ¿cómo estás?, qué bueno que viniste. Este ametrallamiento de palabras me dejó claro que el asunto era grave; al preguntarle cómo se sentía dijo, yo muy bien, qué bueno que viniste para conocerte, en un rato llega mi taxi porque me voy al aeropuerto, voy a encontrarme con Ravi, nos vamos a Indonesia, qué bueno conocerte, ¿quieres tomar algo?, ¿quieres comer? La cosa iba a ser complicada pero logré convencerla de venir conmigo a ver un médico. Quien la hospedaba, Amrita, me dijo que tenía una enorme laguna y quise que la revisaran, de arriba abajo. Temí que estuviera drogada y la hubieran violado. En estos casos uno siempre se imagina lo peor.

Hablando un poco más supe que conocía al gurú Ravindra desde Canadá, que era su tercer viaje a la India y que lo amaba intensamente. ¿Lo amas de un modo espiritual?, pregunté, y ella dijo, sí, y también como mujer, ya me acosté con él, somos muy felices juntos. Amrita me miró con ojos desorbitados $\mathrm{y}$, en un aparte, opinó que eso no era más que una ensoñación, parte de su obsesión por Ravi. Me quedé aún más perplejo. Muchos de estos gurús tienen acusaciones de violación, sobre todo de mujeres occidentales que caen en sus manos, mentes más débiles que quedan subyugadas y, por eso mismo, se entregan en cuerpo y alma. Sobre todo en cuerpo. Afortunadamente este no fue el caso, o al menos eso dijo el médico, que la recluyó en el hospital durante una semana. Luego vino su madre y la llevó de regreso a Tokio, donde cursaba un doctorado. Al irse, el médico me dijo que había encontrado en la orina sustancias psicotrópicas, ¿se drogaba?, ¿la habían drogado? Nunca pude saberlo.

Otro de los personajes claves en la oficina era Madhubán Sharma, mi asistente en temas culturales y el encargado de prensa, nacido en la región norteña de Bihar, la más pobre del país, en una ciudad de nombre para mí impronunciable. Madhubán tenía 24 años, hablaba perfectamente el español y soñaba con ser un famoso gurú. Su ídolo era Osho, el gurú rico, quien llegó a tener 99 automóviles Rolls Royce en su feudo libre de Estados Unidos. Madhubán, para ello, se registró en la oficina 
de patentes de Delhi como gurú con el nombre de "Gurú Rishiraj", y a partir de ese día empezó a firmar con los dos nombres, Madhubán Rishiraj Sharma. Era su sueño desde niño. A los nueve años el cocinero de su casa, Abi, le preguntó qué quería ser cuando grande y él respondió sin titubear: quiero ser un gurú muy rico y vivir en los Estados Unidos. Luego Madhubán le preguntó a Abi qué quería ser él, y Abi le respondió: quiero seguir siendo tu cocinero cuando seas un gurú rico en Estados Unidos.

La historia de Madhubán era trágica. Su padre, un político de Bihar que intentó luchar contra la corrupción, había sido asesinado en 1993, y al parecer en el crimen participaron sus hermanos menores, los tíos de Madhubán, que querían quedarse con las propiedades del padre. Eran dueños de la plaza de mercado de la ciudad, lo que le daba una jugosa renta, pues la alquilaba por espacios a los comerciantes. El abuelo, un filósofo especialista en los Vedas, dictaminó que la herencia iría a parar a la madre de Madhubán, así que los hermanos intentaron matarla. Curioso por esa disputa familiar, le pregunté: ¿y lo intentaron de forma lenta, con venenos o cosas así? No, señor, me dijo, le dispararon varias veces. Él era todavía un niño. Vivieron bajo la protección del abuelo, casi inválido por la obesidad, pues pesaba cerca de doscientos kilos. La madre era de Bombay y por ese motivo no era muy querida en las tierras del padre. Los biharenses emigran a Maharashtra, la provincia de la que es capital Bombay, y allá son tratados como peones de arreo, trabajadores de bajo nivel con salarios irrisorios. Por eso los de Bihar les tienen rabia a los de Bombay. Para empeorar las cosas el padre de Madhubán, un hombre de espíritu progresista, se casó sin dote, pues decía que eran esas las tradiciones que mantenían a la India en el atraso. Fue un golpe duro para la familia.

II.

Muy pronto hará un año que llegué a vivir a Nueva Delhi, y la verdad es que aún no salgo de mi asombro. A los pocos meses le escribí a alguien: "Me siento atrapado por un verso de Emerson en el que Brahma dice: When me they fly, I am the wings (Cuando huyen de mí, yo soy las alas)". Pero esto obviamente no es cierto o, al menos, no de ese modo. Es una verdad poética. Me extraña que Delhi tenga tan poca poesía siendo la capital de un país tan lírico, el único que conozco cuyo 
himno es un poema de un poeta célebre, Rabindranath Tagore. Como si la letra de La Marsellesa fuera de Paul Verlaine o un largo Caligramme de Apollinaire. Los franceses le habrían sacado provecho, pero los indios apenas lo mencionan. Vale decir que también el himno de Bangladesh es de Tagore, lo que no le resta valor a ninguno de los dos. Él era bengalí y su patria estaba en lo que hoy son dos países. La verdad es que Delhi tiene poca lírica, e incluso pocas novelas.

En cambio, al poco tiempo de llegar, invitado por el poeta Sudeep Sen al Festival de Poesía de Delhi, escuché estupefacto a un poeta indio recitar un poema sobre el M16, el servicio secreto británico en el que trabaja, creo, James Bond. En vano he buscado versos que hablen de India Gate, del bello Lodhi Garden, de la monumental mezquita de Jama Masjid o del abigarrado Chandni Chowk. Tal vez tardaré un poco en encontrarlo, no puede ser. Lo que sí está en las repisas de todos es un libro de viajes de un escocés llamado William Darlymple, La Ciudad de los Jins, sobre un año en Nueva Delhi. Es el best seller de la comunidad de expatriados, pues cuenta lo que le pasa a todo el mundo al llegar: el calor y los apagones de luz y esas cosas, salpicado con historias de la época colonial y algunas notas de cultura india. Está en la categoría de libros de viaje que refieren lo lejos que el autor se fue de su casa y las cosas extrañas que comió, pero en fin. Ya dije que no hay mucho. Paul Theroux ha escrito muy bien sobre la India, pero está esparcido en varios libros. Por cierto que Elefanta Suite, el último, es extraordinario.

Cuando supe que iba a venir a la India pensé que debía leer a Tagore y a Kipling, pero la verdad es que me he pasado el tiempo leyendo a V. S. Naipaul. Le tengo simpatía a Kipling por haber nacido el mismo día y el mismo año que él, cien años después, y sobre todo por El Libro de la Selva, que llenó mi infancia de imágenes sobre la amistad. Luego vinieron Kim y sus cuentos, pero esa India colonial, con la miseria local como telón de fondo, me dejó algo perplejo. Era más real Naipaul. Naipaul escribió y retrató un país más parecido al que yo llegué hace un año, es decir una sociedad inmersa en unas tremendas contradicciones: con una pobreza que yo no conocía y, asimismo, con una oligarquía cuyas riquezas harían palidecer a nuestros ricos latinoamericanos - hay 9 indios en los primeros 50 lugares de la lista Forbes - , todo en las mismas polvorientas calles: el absurdo Ferrari color zanahoria sorteando huecos y rickshaws y vacas, y la mujer con un bebé desnudo que defeca sobre el andén mientras pide limosna. 
Las palabras de Naipaul tras su primer viaje son muy claras: "Ningún otro país que yo conociera tenía tantos estratos de desdicha, y pocos países tanta población. Me dio la impresión de que estaba en un continente que, aislado del resto del mundo, había sufrido una catástrofe misteriosa". Naipaul vino a mediados de los años sesenta, hace cuarenta años. Por supuesto que hoy la India ha avanzado espectacularmente. Un mes después de mi llegada, en noviembre de 2008, ocurrieron aquí tres hechos bastante reveladores.

1) Por primera vez un cohete espacial indio no tripulado salió al sistema solar con destino a la Luna. El cohete se llamaba Chandrayaan-1, que en sánscrito quiere decir "vehículo lunar". Partió de la base de Sriharikota y tardó 16 días en llegar, convirtiendo a India en miembro del selecto club de países que cuentan con naves orbitando el plateado disco lunar. Buscaban elio-3, un isótopo escaso sobre la Tierra, muy útil para la fusión nuclear e importante fuente de energía. Antes de partir los científicos se recogieron en un templo hindú para pedir ayuda a los dioses. El vuelo se hizo sin contratiempos y ya se prepara un segundo viaje.

2) El joven novelista Aravind Adiga ganó el Man Booker Prize en Londres, lo que equivale a decir: el más importante premio literario de la lengua inglesa. Y lo hizo con su primera novela, The White Tiger. Adiga nació en Madrás (o Chennai) en 1974 y vive entre Bombay, Londres y los Estados Unidos. El premio fue muy comentado en la prensa. The Times of India hizo una larga nota crítica más bien negativa. Algunos escritores opinaron sobre Adiga y dijeron que su visión del país era la de un turista extranjero, que se detenía demasiado en la pobreza y otros elementos de exuberancia visual, renunciando a las profundidades. Fue el libro más vendido en India durante varios meses.

3) El ajedrecista indio Viswanathan Anand, de 38 años, se proclamó en Alemania campeón mundial de la Federación Internacional de Ajedrez tras hacer tablas en la última partida con el ruso Vladimir Kramnik (resultado final 6,5-4,5). Es su tercer título del mundo tras los conseguidos en 2000 y 2007. Anand ganó las partidas tercera y quinta, jugando con negras, y la sexta, con blancas. Kramnik sólo consiguió vencer en la décima, también con blancas.

Estos tres hechos hablan de una sociedad educada, exquisita y con muy altos niveles de tecnología. Y es cierto, esa sociedad existe, pero convive simultáneamente con "estratos de desdicha" que pueden 
verse en las siguientes cifras: 2.230 .000 niños muertos de desnutrición por año; 720 millones de pobres, de los cuales 400 con menos de 1 dólar al día; carencia de agua potable, ni siquiera en las ciudades importantes; cortes permanentes de luz; inexistencia de un salario mínimo; violencia religiosa en la que, el Islam, con 160 millones de personas, es una minoría constantemente agredida, avasallada y en desigualdad de oportunidades; 120.000 .000 de "intocables", la casta más baja en el sistema religioso hindú, los cuales son tratados poco menos que como animales y que, a pesar de todo, han logrado triunfos aislados y participación en política. El país en cuyos semáforos piden limosna las formas más horripilantes y crueles de la miseria humana es el mismo que acaba de firmar un contrato con Estados Unidos por 30.000 millones de dólares para actualizar arsenales defensivos, ¿cómo puede ser esto posible?

La primera vez que atravesé la ciudad, de lado a lado y por la zona sur, fue sobre todo una experiencia visual. Con gran curiosidad, sentado en el asiento trasero de un Ambassador, me dediqué a mirar por la ventana. Vi avenidas cubiertas de árboles de sombra y enormes casas desconchadas, terrenos de más de una hectárea rodeando elegantes bungalows oficiales, rickshaws color verde y amarillo brotando como insectos, esa pobreza inhumana en esquinas y semáforos, el tráfico colosal y la enorme sabiduría para no enloquecer en medio de semejante caos. Pero nadie parecía enloquecer sino todo lo contrario. Incluso una silenciosa mayoría, sentados en los muros de las calles y con expresión ausente, daban la impresión de ser moderadamente felices. Hay formas de felicidad que pueden ponerle a uno la carne de gallina, y ésta puede ser una de ellas.

Lo sagrado. Pocos países como éste tienen tantos dioses, tantas cosas sagradas. El panteón hindú es tan superpoblado como el subcontinente. Se le calculan 3.600.000 dioses, a lo que se debe sumar el islam, el cristianismo, el jainismo, el budismo, el judaísmo y otras religiones minoritarias como los parsis. Por este motivo casi todo es sagrado: la montaña y el río (el Ganges), ciertos árboles bajo los cuales se hace meditación, muchos animales-dioses, como el mono Hanumán, y por extensión todos los monos, o el elefante Ganesh, y por extensión todos los elefantes. Otros dioses hindúes convirtieron en sagradas a las ratas, a las serpientes. Casi todo lo que existe o se mueve es sagrado para alguien en India. Los jainistas no comen productos extraídos de la tierra por miedo a que en ellos haya bacterias, que son formas de vida y por 
lo tanto ellos veneran. La tierra, el aire y el fuego son sagrados para los parsis, de modo que ni entierran ni incineran a sus muertos sino que los dejan en unas parrillas elevadas, llamadas "torres del silencio", para que los buitres y gallinazos se los coman.

La vida cotidiana en Nueva Delhi está repleta, casi diría invadida de estas cosas. Tras alquilar un apartamento uno aprende, por ejemplo, que sólo determinadas castas bajas tocan la basura. Un hombre viene todos los días y se lleva la bolsa con los desperdicios. Ni siquiera las empleadas la tocan. Casi ni lo miran a los ojos. Cuando uno sale a la calle y ve toneladas de basura esparcidas, la inmundicia que rebosa por todo lado, comprende que estos hombrecillos, los de la basura, no dan abasto. Nadie que no sea de esa casta pensaría un solo segundo en agacharse a recoger algo del suelo. Un día vi a un joven bajar la ventana de un carro elegante y tirar un paquete de papas fritas al suelo. Lo miré con curiosidad y él, sintiéndose retado, me dijo desafiante: "Esto no es Estados Unidos, esto es India". Acto seguido escupió una baba roja, de mascar hoja de betel, que dejó manchado el asfalto, ya bastante asqueroso. Esta mancha roja, el escupitajo de betel, es como la firma de la ciudad en casi todos sus muros. Es difícil encontrar uno, incluso al interior de edificios públicos, que no tenga esa huella color chocolate que es el rojo ennegrecido. El sistema de castas está en el origen de esa inmundicia, tan visible en toda la India. ¿Por qué limpiar?, ¿por qué recoger algo? Ya habrá alguien que tiene la obligación de hacerlo.

¡La basura! El tema de la suciedad en India está en muchas conversaciones de extranjeros. Pretender ignorarla, como hacen algunos en actitud políticamente correcta, es hipócrita e incluso paternalista. También es una bobería el contrario: ver sólo la inmundicia y limitar la visión de India a eso, sin ir más allá. Pero, ¿cómo negar que las calles de Delhi o Calcuta son en la práctica gigantescos vertederos de basura, polvo y escupitajos, sanitarios horizontales de materias fecales humanas y animales, surtidores de olores homicidas, charcas infectas repletas de detritus y podredumbre, muy visitadas por moscas y demás insectos asiduos a la cercanía de la mierda? Por contraste, los parques de Delhi son en cambio muy limpios y cuidados, y entonces uno se pregunta, ¿por qué? La suciedad no es sólo explicable por la pobreza. La pobreza y la suciedad no son sinónimas. Pero la gente amolda el ojo y ya no percibe la inmundicia. De cualquier modo tampoco harían nada por evitarla. 
Esto es una gran característica del subcontinente: nadie parece muy dispuesto a hacer nada que no esté en el área específica de su trabajo. Pedirle a un chofer que ayude a cambiar un bombillo es ofenderlo. La cocinera no tocará jamás la plancha. Para colmo, las castas también asoman la nariz en esto: hay castas de recicladores, de trabajadores del cuero (que tienen contacto con piel muerta), de transportadores. Incluso hay una casta de ladrones, que deben robar para cumplir con su dharma o destino o identidad o fortaleza.

El dharma es lo primero, casi lo único. Luego uno puede echarse a dormir, y de hecho es una de las cosas más frecuentes en Delhi. A cualquier hora del día la gente duerme profundamente en las calles, en los lugares más incómodos y en posiciones circenses. En un rickshow, en medio de un morro de arena repleto de moscas, en el separador de una avenida, sobre una bicicleta recostada a un muro. Duermen. Silencio. Los amantes de la espiritualidad india ven en esto una expresión de paz, e incluso dicen: "En Occidente tomamos pastillas para dormir y aquí la gente duerme bajo la lluvia". Es verdad, casi nada los despierta, pero al parecer las razones no son tan románticas. Lo que los hace dormir son dos cosas: la desnutrición y el alcoholismo. La extrema delgadez, la falta de proteína animal y la ínfima ingesta calórica crean estos cuerpos filiformes que parecen estatuas de Giacometti, y que tras el mínimo esfuerzo caen exhaustos. Además muchos beben alcohol, unas botellitas de cuarto de litro que compran en las licoreras estatales. Supongo que se necesitan muy pocos tragos para llevar a la ebriedad esos espíritus tan frágiles. También la profunda belleza de esos ojos negros, en los niños, es una muestra de desnutrición. Según me explicaron, cuando el cuerpo está subalimentado envía señales de auxilio y una de ellas está en los ojos. Ojos brillantes, bellos, que llamen la atención. Su belleza es un grito que dice, ayúdame. Un S.O.S.

Es interesante ver las primeras impresiones de otros residentes o viajeros. Octavio Paz llegó en 1951 como Primer Secretario de la embajada de México. Esto escribió en Vislumbres de la India: "Nueva Delhi es irreal", "Nueva Delhi no fue edificada lentamente, a través de los siglos y la inspiración de sucesivas generaciones, sino que, como Washington, fue planeada y construida en unos pocos años por un arquitecto: Sir Edward Lutyens. A pesar del eclecticismo del estilo —una visión pintoresca de la arquitectura europea clásica y de la India - el conjunto no es sólo atractivo sino, con frecuencia, imponente. Las grandes moles 
marmóreas del antiguo palacio virreinal, hoy residencia del presidente de la República, tienen grandeza. Sus jardines de estilo mongol son de un trazo perfecto y hacen pensar en un tablero de ajedrez en el que cada pieza fuese un grupo de árboles o una fuente. Hay otros edificios notables en el mismo estilo híbrido. El diseño de la ciudad es armonioso: anchas avenidas plantadas de hileras de árboles, plazas circulares y una multitud de jardines. Nueva Delhi fue concebida como una ciudad jardín. Por desgracia, en mi última visita, en 1985, me sorprendió su deterioro. El excesivo crecimiento de la población, los autos, el humo que despiden y los nuevos distritos, casi todos construidos con materiales baratos y en un estilo chabacano, han afeado a Nueva Delhi".

El deterioro continuó y en el 2008 ya fue tanto que, a mi llegada, la ciudad estaba toda en obra. No sé si sea imaginable lo que supone para una urbe de 16 millones de habitantes el construir, al mismo tiempo, una ambiciosa ampliación del Metro a todo lo ancho y largo de su superficie, trazar nuevos puentes y anillos de circulación, elevar puentes, ensanchar avenidas para instalar el sistema de transporte rápido en buses que en Colombia se llama Transmilenio y aquí BRT, y, como si fuera poco, haciendo un monumental proyecto de obras de mejora de infraestructura de la ciudad con miras a octubre 2010, cuando Delhi será la anfitriona de los Juegos del Commonwealth. ¡Todo simultáneamente!

Al polvo que los vientos del norte traen desde los desiertos del Rajastán, y que deja una pátina grisácea sobre las hojas de los árboles y los edificios, sobre calles y jardines, viene a sumarse el polvo de las excavadoras, las dragas, las grúas y los bulldozers que van y vienen, los camiones de materiales, y en medio de todo eso, como figuras irreales en un cuadro de dolor, las mujeres cargando en sus cabezas canastas de ladrillos rojos, con sus hijos pequeños alrededor, desnudos, jugando en los morros de arena. Si uno mira los planos urbanísticos verá que a orillas del Jamuna planean hacer hoteles y restaurantes, algo que, a primera vista, parece sencillamente irrealizable, pues el Jamuna es un lodazal que milagrosamente aún fluye, tanta es la inmundicia y detritus que recibe a su contacto con Delhi. Sus orillas son pantanos cenagosos, y por eso imaginar que en ese mismo lugar habrá exclusivos restaurantes, hoteles de lujo y centros comerciales, parece ciencia ficción, aunque no hay que presuponer nada, pues el ímpetu del trabajo y la enorme cantidad de recursos podría, al cabo de un tiempo, llegar a lograrlo. 
Otro viajero a quien admiro, que llegó a Delhi en 1958 procedente de Varsovia, fue el periodista y escritor Ryszard Kapuscinski. Venía a escribir reportajes para el diario Sztandar Mlodych, luego de que Jawajarlal Nehru visitara Polonia, siendo el primer presidente en venir de visita oficial desde un país que no pertenecía a la esfera de influencia de la Unión Soviética. Kapuscinski llegó de noche al aeropuerto y, como nadie lo esperaba, tomó un taxi que lo llevara a un hotel. Puedo imaginar su extrañeza al internarse en la oscuridad de las calles aledañas al aeropuerto, intentando comprender dónde estaba y cómo era la ciudad. Ese momento lo describe así: "Ante nosotros, en el lugar que debía ocupar la carretera, vi un río blanco y ancho cuyo fin se perdía en el lejano fondo de la espesa oscuridad de una noche húmeda y sofocante. Aquel río estaba formado por personas que dormían a la intemperie; unas estaban tumbadas sobre unos catres de madera, otras sobre esteras y mantas, pero la mayoría cubría con sus cuerpos el asfalto desnudo y la arena que lo flanqueaba por ambos lados (...). A medida que avanzábamos, se fueron levantando uno tras otro para echarse a un lado, no sin llevarse a los niños y dar empujones a unas ancianas que apenas podían caminar. En su celosa mansedumbre, en aquella sumisa humildad, se encerraba una actitud de vergüenza y de disculpa, como si al dormir sobre el asfalto aquella gente hubiese cometido un delito cuyas huellas intentase ocultar lo más deprisa posible (...). Luego, ya en la ciudad, también las calles resultaron poco transitables, pues todas ellas parecían un gran campamento de nómadas, habitado por fantasmas nocturnos vestidos de blanco, sonámbulos y dormidos".

Los durmientes en las calles de la India son un duro espectáculo. Los he visto y veo a diario en las cercanías de la tumba Humayún. Es realmente imposible no sentir un arañazo en la conciencia y en las tripas ante estos seres desharrapados, sucios, flacos como espigas, alzando niños desnudos, bebés que gatean sobre la tierra del separador o que juegan en un charco en el que flotan desperdicios. Los andenes, por eso, están llenos de comida, basura, excrementos. En Benarés (llamada hoy Varanasi) hice el paseo por el Ganges al amanecer y para ello debí atravesar a pie el centro de la ciudad a las cuatro y media de la mañana. Me impresionó la gente durmiendo a la intemperie, bultos esparcidos por los bordes de las calles, uno tras otro, una línea infinita en diversas posiciones, metidos entre sacos de tela o esparto, cubiertos con mantas sucias, pelambres y cabelleras entierradas surgiendo de montañas de harapos, en medio de la basura. 
Otras ciudades de la región, como Bangkok o Yakarta, y ya no digamos Singapur, parecen relucientes tazas de porcelana. Katmandú y Dakkha, en cambio, son tan polvorientas y sucias como las ciudades indias. Pero Delhi y Calcuta y Bombay tienen algo especial, y es una vibrante vida cultural. Sospecho que en Delhi hay más librerías que en París, y los recitales de poesía a los que se puede asistir en Calcuta no tienen parangón. Ni hablar de las artes plásticas. India es una sociedad compleja, indisciplinada, a veces violenta, pero es una sociedad tremendamente culta. Aquí hay filosofía, sociología, hay debate político, y por supuesto mucha literatura. Creo que el próximo Nobel indio será Vikram Seth antes que Salman Rushdie, entre los escritores de expresión inglesa. Alrededor, en lenguas menos conocidas como el tagalu, el maharashtra, el tamil o el mismo bengalí, hay una gran literatura, muy viva. Una visita a la Feria del Libro de Delhi me dejó impactado, ¡cuántas editoriales en idiomas diversos y cuántos libros! Porque los indios leen mucho. Lo leen todo y lo discuten todo. Hay 2.500 periódicos y 74 partidos políticos. Uno los ve sentados en sus bancas con periódicos abiertos. En los buses y el metro. En medio de esas polvorientas y sucias calles en las que, de cualquier modo, seguiré viviendo, pues en ellas uno puede encontrar el horror pero también toda la belleza del mundo.

\section{III.}

El juez Sistani Singh es un sij de 54 años, un metro sesenta y cuatro de estatura y una mirada penetrante que debe usar cual daga en sus peroratas legales, pues es miembro de la Corte Suprema de Justicia de la India y, recientemente, nombrado juez anticorrupción, durante el gobierno de Mahmohan Singh, otro sij (todos los sijs se apellidan Singh). Su esposa Honey es ama de casa, como ordenan los cánones locales, y sus dos hijos estudian el bachillerato. Su hermano es también abogado pero no ha tenido su mismo éxito, y su madre, viuda, vive aún. Las tres familias comparten un típico edificio de Nueva Delhi en el barrio de Jangpura Extention, una construcción clásica de tres pisos al frente de un parque. En el primer piso vive la madre, en el segundo el hijo menor y en el tercero el juez Sistani, jefe de familia desde la muerte del padre. Que residan en un mismo inmueble es común en este país. 
Cuando se celebra un matrimonio la joven novia va a vivir con el marido a la casa de sus suegros. Por eso en India todos los cuartos de las casas tienen baño completo (sanitario, lavamanos y ducha). Si hay cinco cuartos habrá cinco baños, algo impensable en Europa. Cada uno, con el tiempo, podrá convertirse en el pequeño apartamento de una familia.

Para los Sistani las cosas son diferentes.

En lugar de un apartamento tienen un edificio entero, y el tercer piso, o segundo en términos de India, es un bello espacio con tres grandes habitaciones, dos terrazas y un salón comedor enorme, ocho metros de puerta-ventana hacia el parque y el cielo toldado y contaminado de Delhi. En él crecieron felices los hijos, y Honey fue la mujer más plena. Por ser la nuera mayor fue la de la autoridad en la familia, hizo amistades en todo el barrio, disfrutó del Eros Cinema (no es un cine erótico, en India ese nombre es muy común), revoloteó en el mercado de Boghal y conoció sus entresijos, gozó de la curiosa oferta de Novelty, mezcla de tienda de esquina con alquiler de videos y, sobre todo, expendio de deliciosos sandwiches de atún con picante, unos paninis indios que ella adoró desde el primer día que pasó en Jangpura, barrio de clase media acomodada en la zona sur de la ciudad, equidistante de Defence Colony, una zona más cara con restaurantes y bares al estilo occidental, y de Nizzamudin West, barrio musulmán algo inferior en estatus pero muy vivo, con una mezquita importante y, sobre todo, con la tumba de Nizzamudin, cultor del sufismo en India, gracias a lo cual todos los jueves a las cinco de la tarde hay cantos sufíes a capela o con acompañamiento de armonio. En Nizzamudin West está el restaurante Karim, el más famoso de Delhi por su pollo tandoori, una verdadera delicia que, además, sirve a domicilio.

La alegría de Honey iba a cambiar, aunque no por una tragedia, como suele pasar en las películas (también en las de Bollywood), sino por un acontecimiento feliz, que fue la promoción del magistrado Sistani a juez anticorrupción del Estado, lo que le valió subir en la escala jerárquica a uno de los puestos más importantes de la magistratura india y, como suele suceder aquí, acceder a una serie de canonjías y privilegios, entre los cuales está el disfrute de un bungalow oficial en la zona de avenidas aledañas a India Gate, una de las más exclusivas, un palacete con una hectárea de jardín alrededor, dos pisos, nueve empleados, carro oficial con chofer y guardaespaldas, más jardinero y vigilante. Por este motivo los Sistani dejaron Jangpura Extention. 
Yo no sabía nada de todo esto cuando alquilé su apartamento.

Un gestor e intermediario de finca raíz, Abishek, nos propuso la casa, Analía la vio mientras yo estaba en México - por cierto invitado al cumpleaños 80 de Carlos Fuentes, desde aquí un nuevo abrazo, maestro- $y$, al llegar, nos decidimos. Tres habitaciones con baño cada una. Ciento setenta metros, dos balcones, vista despejada hacia ambos lados. Ochenta mil rupias. Nos pareció ideal.

\section{IV.}

Es martes y la peluquería y barbería de Nizzamudin East está cerrada, lo que me supone un pequeño problema ya que tengo el pelo y la barba muy largos y esta misma noche debo viajar a Tokio por trabajo, lo que quiere decir que conviene estar presentable. Es extraño que la peluquería esté cerrada, pues todos los comercios vecinos tienen sus puertas abiertas, así que camino hasta la siguiente barbería de la calle comercial del barrio. Cerrada también. ¿Será que el martes, para los barberos, es como el "lunes del zapatero"? Pregunto a Peter, mi fiel conductor, quien me explica que los martes las peluquerías de hinduistas están cerradas debido a un pasaje del Mahabarata en el que se dice que ese día está prohibido hacerse cambios en el cuerpo.

Pero Peter tiene una solución para todo así que vamos al mercado de Boghal, en Jangpura Extention.

-Esta barbería es musulmana —me dice señalando un local bastante tremebundo y sucio, aunque con intención de ser moderno-, estará abierta.

Se llama Jawed Habib, Hair Beauty. Salta a la vista que es musulmana y está abierta. El tráfico de Hospital Road y los pitos y ruidos del mercado de Boghal desparecen, pues la Jawed Habib es un ancho corredor lleno de sillones, espejos cortados en forma de diamante y unos frescos sobre las paredes bastante kitsch de jóvenes occidentales bailando y jugando con su pelo, algo que recuerda el afiche de la película "Hair".

El peluquero me ofrece un café y me mira. Es joven y amanerado. Amable. Le explico lo que quiero, nada extravagante: sólo un corte de un par de centímetros, también la barba. Pasado un rato me pregunta si soy musulmán. Le contesto que no y pregunta de nuevo: ¿el señor es afgano? Le digo que no. ¿Cachemiro? Vuelvo a negar. Me mira perple- 
jo. ¿Cristiano? Sí, le digo, sí. Menciono mi país y me dice, ¿Colombo?, ¿Sri Lanka? Este equívoco es muy común en la región. Colombia queda lejos y nadie piensa que uno pueda venir de allá. Será Colombo, la bella capital de Sri Lanka. Vuelvo a decirle que no y le explico, Sudamérica, entonces sonríe y dice, ah, sí, Sudamérica, me gusta el fútbol, así que le pregunto, ¿le gusta Maradona?, pero hace un gesto de sorpresa y dice no, no lo conozco, no señor, entonces yo insisto, ¿Pelé?, no señor; le nombro otros futbolistas: ¿Zidane?, ¿Beckham?, ¿Messi?, ¿Ronaldo?, pero no conoce a ninguno, así que le pregunto, ¿seguro que le gusta el fútbol?, y él responde con una sonrisa, sí señor, me gusta mucho, muchísimo.

\section{V.}

La velada literaria de la Alianza Francesa, en su espectacular sede junto a los Lodhi Gardens, tiene como título "Bonjour Inde". Asisto a la inauguración, con palabras del embajador de Francia y de algo así como el alcalde de Delhi, quien cita generosamente a Malraux. Los escritores franceses invitados fueron Olivier Germain-Thomas y André Velter, en conversatorio con William Darlymple y el poeta indio Ashok Vajpeyi. Dios santo. El tema del debate era "escribir la India". Partieron de una traducción errónea de Octavio Paz, pues su libro Vislumbres de la India se llama en inglés In Light of India, lo que da pie a decir, ipero si India no estaba en la oscuridad! André Velter, poeta, dijo: "Si uno va a escribir sobre la India debe hacerlo rápido. A los quince días uno sabe mucho y al mes ya sabe todo. Es ahí cuando debe hacerlo. Al año uno sabe menos y a los diez años realmente no sabe nada". Inteligente apreciación. Luego dijo: "Mi amor por India es como cualquier amor, que se fija no sólo sobre lo bello sino también sobre el defecto, la imperfección, sobre lo horrendo de aquello que se ama". Son inteligentes estos franceses: saben decir banalidades de tal forma que parecen ideas, incluso buenas ideas. Se citó un poema suyo sobre la inmensidad de los Himalaya, y dijo: "Me gusta India porque me permite sentir cosas que no existen en ningún otro país del mundo”. ¡Deslumbrante! La verdad es que el más interesante fue el moderador, el poeta Vajpeyi, quien dijo que India, con el tiempo, era como un plato de tali. Explicó que en la comida occidental hay un aperitivo, una entrada, un plato fuerte y un postre; y cada vez se retira el plato antes de traer el siguiente. El tali, en cambio, tiene todo junto: la entrada, el plato fuerte y el postre. "Eso 
es la India. El siglo XII no se retira cuando llega el XIII, ni el XVI ni el XX. Todos los siglos están vivos, todo el pasado está en la calle: la edad media y el siglo diecinueve y la colonia y la época de los Maharajás y el XXI con sus cohetes... Todo simultáneamente". Luego, tal vez atravesado por un rayo de luz poética, dijo: "Los búfalos y las vacas aman atravesar las avenidas y aman recostarse un rato en medio de esas avenidas. Eso es la India”. Fue lo más inteligente que se dijo en toda la velada.

Olivier Germain-Thomas, a quien jamás leeré, fue presentado como escritor y viajero, a lo que él agregó: y filósofo. Muy bien. Su aspecto parecía interesante: físico espigado al estilo de Samuel Beckett, pero en cuanto abrió la boca el parecido terminó. Un típico francés psicorrígido y pretencioso. Acabó diciendo que India era la reserva espiritual del mundo y que él venía aquí a buscar lo que no tenía en Francia. "La modernidad y el siglo XXI están en Japón y en California, eso aquí no me interesa". El viajero que busca la postal étnica, el que se enfurece cuando llega a Asia y comprueba que la gente ya no usa sampanes ni viste faldellines. Es que para ver personas en jeans y con seguro médico y hablando por blackberrys, pues para eso me quedó en París. Si ce pour cela je reste à Paris! Conozco bien a esos europeos adoradores de lo étnico. El mundo en desarrollo es un zoológico donde les gusta ver especies raras. Lo único potable que dijo Germain-Thomas fue una cita de Mozart para la cual pidió silencio y máxima atención: "Componer es reunir notas que aman estar juntas". Muchos en la sala se lo agradecimos.

El otro en la mesa era William Dalrymple, autor de best sellers indios, incluido The City of Djins. Fue el personaje más estrambótico. Vestía kurta negra, sandalias y un shall al hombro. Al sentarse se descalzó y cruzó la pierna, regalándole al público un primer plano de sus asquerosos y sucios pies. Es el tipo de persona que sólo puede hablar riéndose. Creo que es un rasgo de timidez. Me pareció un imbécil. Tal vez un imbécil con talento, eso sí. Contó que en una ocasión, en el siglo XIX, un escocés había muerto en Calcuta y fue repatriado en barco. Por razones higiénicas el ataúd en el que iba el cadáver se llenó de whisky, pero los marineros lo olieron y empezaron a abrirle hoyos para beber hasta emborracharse. Aseguró que la historia era cierta y volvió a reírse. No paró de reírse de sus propias anécdotas ante el silencio de la sala, pero al menos contó algo y se negó a hacer una teoría sobre la India. Tampoco quiso enseñarles a los indios cómo debían vivir, que es lo que, de algún modo y de forma muy natural, hicieron los franceses, que son 
los que saben cómo deben vivir los demás, por lejos que hayan nacido. En el fondo Dalrymple me cayó simpático. Un tipo inseguro. Se le notaba a leguas que no quería estar ahí.

Luego me quedé pensando: es fácil criticar a los demás, pero ¿y yo? Esto me llevó a preguntarme sobre la naturaleza de lo que quiero escribir, es decir, de esto que estamos leyendo ahora, ¿vale la pena? Por supuesto que mis modelos literarios cuando se trata de viajes son Paul Theroux y V. S. Naipaul. Lo que haré no será escribir sobre la India sino escribir en la India. Creo que es algo diferente. Incluso podría decir también, aunque suene a crónica periodística, escribir desde la India.

Hablo de este tema con mi amigo Aparajit Chattophadhyay, profesor de literatura y lengua española en la Universidad Nehru. Le cuento lo que dijeron los escritores franceses y él se ríe, "ellos nunca entenderán nada, no saben cosas esenciales, como que el $70 \%$ de la población de este país, me refiero a la India profunda y rural, jamás ha escuchado mencionar la palabra reencarnación, y si la escucharan no sabrían qué significa", y agrega, "para los europeos todo lo que pasa en la India es consecuencia de la reencarnación". Le hablo de mi libro, de este libro, y me dice: "Por favor, ¡no narres una boda!”. Nos reímos. Es lo más típico, lo que más llama la atención de los extranjeros, y es que de verdad son estrafalarias. Pero después de Un Buen Partido, la genial novela de Vikram Seth, ya no vale la pena narrar bodas indias. Todo está dicho ahí. Por cierto que tuve la suerte de conocerlo gracias a Héctor Abad, que es su amigo. Ya hablaré de esto más adelante. Por ahora sigo con Chatto, en la cafetería de la universidad Nehru. Bebemos un café con leche y azúcar muy dulce. Hace calor, es el principio del verano. Marzo. Acabo de hacer una charla sobre literatura colombiana a sus alumnos. Chatto me dice que la novela Tide Waters de Amitab Gosh es igual que La Vorágine. Que gracias a La Vorágine comprendió mejor a Gosh. No la he leído, le digo (la de Gosh). Promete regalármela. Le pregunto a Chatto por su experiencia en la guerrilla y promete contármelo todo en el próximo encuentro. Iremos a almorzar. Tras el café me muestra una de las casetas universitarias donde se venden libros, cerca del parking. Se ríe y dice: "mira, es una librería especializada en marxismo radical". Hay que recordar que en India ni el viejo socialismo ni el comunismo ni la izquierda en general han muerto. Todo lo contrario, y mucho más en la Universidad Nehru, cuyas paredes están repletas de imágenes del Che Guevara, de Fidel, de Chávez. 
VI.

Una soleada mañana de invierno. Los pitos de los automóviles y rickshaws se oyen a lo lejos, lo mismo que un taladro. El Mail Today trae noticias de la fragilidad y la idiotez humana que, como el espíritu, sopla donde quiera. Esta vez ocurrió en Bilauchpura, un villorrio pobre del distrito de Baghpat, región de Uttar Pradesh. Es una triste historia de jugadores. Los protagonistas son dos campesinos de treinta años, Anees y Rahees, adictos al juego, ludópatas y muy pobres. Lo habían perdido todo a las cartas contra un tercero, Firoz, cuando, para igualar una apuesta de 15.000 rupias (unos trescientos dólares), decidieron apostar a sus esposas, las jóvenes Shabana y Najma. Volvieron a perder y Firoz, no contento con quitarles sus pocas propiedades, quiso cobrar y que le dieran las mujeres, ipretendía que las dos se fueran a vivir con él! Por supuesto Shabana y Najma se negaron, pero por eso sus maridos las golpearon. La cosa no llegó a más pues las mujeres fueron a buscar protección a la policía. Los agresores serán arrestados. El diario cita otros cinco casos de hombres que perdieron a sus mujeres en el juego el último año en India. En uno de ellos la mujer fue violada por cuatro compañeros de juego del marido. También mencionan a un hombre en West Bengala que apostó a su hija de 18 años y la perdió. El acreedor, un musulmán llamado Mustafá, se llevó a la joven y sólo un par de semanas después pudo ser recuperada.

Esto recuerda otro caso, ya no en India. El récord de lo que una persona ha perdido en un casino de Las Vegas. Lo tiene un norteamericano de origen japonés llamado Terrance Watanabe, quien, en el 2007, perdió 127 millones de dólares, la mayoría en el Harrah's Casino. ¿Y quién es este pobre desesperado? Un hijo de japoneses establecidos en Estados Unidos. Terrance heredó una fortuna de 300 millones de dólares y perdió algo menos de la mitad. Aún les debe 15 millones a los casinos, pero anunció que no piensa pagar. Dice que se aprovecharon de su debilidad: que le dieron alcohol, lujosas suites, mujeres, drogas, todo para que siguiera jugando. ¿Y el libre albedrío? Los casinos argumentan que es un adulto que firmó pagarés y que si hubiera ganado ellos sí le habrían pagado. ¿Quién tiene razón? 